\title{
Caesarean myomectomy: a descriptive study of clinical outcome
}

\author{
Tapan Pattanaik ${ }^{1}$, Basanta Kumar Pati ${ }^{1}$, Sunita Samal ${ }^{2} *$
}

\author{
${ }^{1}$ Department of Obstetrics and Gynaecology, Institute of Medical Science and Sum Hospital, Odisha, India \\ ${ }^{2}$ Department of Obstetrics and Gynaecology, MGMC \& RI, Puducherry, India
}

Received: 21 January 2014

Accepted: 2 February 2014

\author{
*Correspondence: \\ Dr. Sunita Samal, \\ E-mail: sunisamal@rediffmail.com
}

(0) 2014 Samal S et al. This is an open-access article distributed under the terms of the Creative Commons Attribution Non-Commercial License, which permits unrestricted non-commercial use, distribution, and reproduction in any medium, provided the original work is properly cited.

\begin{abstract}
Background: The objective was to analyse the clinical outcome of caesarean myomectomy and to evaluate the safety of performing the procedure.

Methods: A total of 23 cases of caesarean myomectomy, conducted in Institute of Medical Science and Sum Hospital Odisha, between January 2008 to December 2012 were analysed.

Results: In this study, out of 23 cases one case needed hysterectomy and another one required relaparotomy. Puerperal pyrexia and sepsis was found in $8.6 \%$ cases and $60.8 \%$ cases had post-operative anaemia. Intra operative haemorrhage was more than $1000 \mathrm{ml}$ in $82.6 \%$ cases though only30.4\% cases required blood transfusion. Hospital stay in all patients was on average 8 days post-operatively. There was no maternal or perinatal mortality.

Conclusion: Myomectomy is relatively safe during caesarean section in selected cases with expert hand.
\end{abstract}

Keywords: Caesarean section, Leiomyoma, Myomectomy

\section{INTRODUCTION}

Pregnancy complicating leiomyoma and leiomyoma complicating pregnancy are frequently encountered by the obstetrician. Uterine leiomyoma is found in approximately $2 \%$ of pregnant women. ${ }^{1}$ This association is mainly seen in elderly primigravidas. Myomectomy at time of caesarean delivery has traditionally been discouraged. With the exception of small, pedunculated fibroids, most of the leading obstetric textbooks advice against myomectomy during caesarean delivery due to theoretical risks of intractable haemorrhage and increased postoperative morbidity. ${ }^{2,3}$ Myomectomy as a separate procedure during caesarean increases the haemorrhage by about $10 \%{ }^{4}$ while at the same time it can avoid second surgery. Uterus in the postpartum period is better adapted physiologically to control haemorrhage by contractions and retractions and we can take this advantage by doing caesarean myomectomy. Recent reports suggest, myomectomy in experienced hands is possible and safe. ${ }^{5}$ In an attempt to define the risks of myomectomy during caesarean delivery, we looked at our five year experience at our institution with the procedure and to analyse the clinical outcome.

\section{METHODS}

This was a descriptive study of 23 patients of caesarean myomectomy done between Jan 2008 to Dec 2012 in Institute of Medical Science and Sum hospital, Odisha. All the pregnant women who were diagnosed to have fibroid either by antenatal ultrasonography or incidentally found intra-operatively were included in the study. Those who had history of antepartum haemorrhage and where other procedure like ovarian cystectomy was performed were excluded. A detailed history was obtained from all the patients. Clinical examination and routine investigations were done and analysed. All the data on age, parity, gestational age, indications for caesarean section were retrieved. Other information abstracted were total time taken for the surgery, location of the fibroid, type and sizes of fibroids removed, estimated blood loss at surgery, 
requirement of blood transfusion and complications encountered. As a protocol in our hospital all the patients were given oxytocin infusion for 12 hours post operatively and all of them were received broad spectrum antibiotics. All were followed up till 6wk after caesarean section with clinical examination and ultrasonography.

\section{RESULTS}

A total of 23 patients of caesarean myomectomy performed between Jan 2008 to Dec 2012 in Institute of Medical Science and Sum hospital, Odisha were included in the study. In our study the mean age was $31.2 \mathrm{yrs}$ and majority of patients were in 31-35yr age group (43.4\%) (Table 1a). Most of the patients were primigravida (69.5\%) and $78.2 \%$ of cases were at term (Table 1b,c). Fetal distress $(30.4 \%)$ was the commonest indication of caesarean section and only in $17.3 \%$ cases caesarean was done due to presence of fibroid in lower uterine segment (Table 2). Emergency surgery was performed in 14 patients while 9 patients had undergone elective caesarean (Table 3). Intraoperatively $51.7 \%$ were non-pedunculated and $48.27 \%$ were pedunculated fibroid. Most of the fibroids were less than $5 \mathrm{~cm}(51.7 \%)$, whereas $41.3 \%$ were $5-10 \mathrm{~cm}$ and only $6.8 \%$ were more than $10 \mathrm{~cm}$ in size (Table 4). Though 19 patients had intraoperative blood loss of more than one litre, only 7 patients required transfusion (Table 5). With regards to the outcome of caesarean myomectomy $60.8 \%$ developed anaemia while only one patient required subtotal hysterectomy, one required relaparotomy and 2 patients developed puerperal sepsis (Table 5).

Table 1a: Age distribution $(n=23)$.

\begin{tabular}{|lll|}
\hline Age in years & No. of patient & Percentage \\
\hline $26-30$ & 7 & 30.4 \\
\hline $31-35$ & 10 & 43.4 \\
\hline $36-40$ & 5 & 21.7 \\
\hline $41-45$ & 1 & 4.3 \\
\hline
\end{tabular}

Table 1b: Parity distribution $(n=23)$.

\begin{tabular}{|lll|}
\hline Parity & No. of patient & Percentage \\
\hline Primigravida & 16 & 69.5 \\
\hline Multigravida & 7 & 30.4 \\
\hline
\end{tabular}

Table 1c: Gestational period $(n=23)$.

\begin{tabular}{|lll|}
\hline Gestational age & No .of patient & Percentage \\
\hline Preterm & 3 & 13.0 \\
\hline Term & 18 & 78.2 \\
\hline Post term & 2 & 8.6 \\
\hline
\end{tabular}

Table 2: Indication of caesarean section $(n=23)$.

\begin{tabular}{|lll|}
\hline Variables & Number & Percentage \\
\hline Fetal distress & 7 & 30.4 \\
\hline Malpresentation & 3 & 13.0 \\
\hline $\begin{array}{l}\text { Uterine fibroid in lower } \\
\text { segment }\end{array}$ & 4 & 17.3 \\
\hline Previous LSCS & 4 & 17.3 \\
\hline Non progress of labour & 2 & 8.6 \\
\hline Cephalopelvic disproportion & 3 & 13.0 \\
\hline
\end{tabular}

Table 3: Timing of surgery $(n=23)$.

\begin{tabular}{|lll|}
\hline Variable & Number & Percentage \\
\hline Elective & 9 & 39.1 \\
\hline Emergency & 14 & 60.8 \\
\hline
\end{tabular}

Table 4: Fibroid characteristics $(n=29)$.

\begin{tabular}{|lll|}
\hline Variables & Numbers & Percentage \\
\hline \multicolumn{2}{|l|}{ Type of fibroid removed $(\mathbf{n = 2 9 )}$} & \\
\hline $\begin{array}{l}\text { Non pedunculated fibroid } \\
\text { (intramural, subserous, } \\
\text { submucous) }\end{array}$ & 15 & 51.7 \\
\hline Subserous pedunculated & 14 & 48.27 \\
\hline Size (n=29) & & \\
\hline$<5 \mathrm{~cm}$ & 15 & 51.7 \\
\hline $5-10 \mathrm{~cm}$ & 12 & 41.3 \\
\hline$>10 \mathrm{~cm}$ & 2 & 6.8 \\
\hline
\end{tabular}

Table 5: Outcome of all caesarean myomectomy $(n=23)$.

\begin{tabular}{|lll|}
\hline Variables & Number & Percentage \\
\hline Estimated blood loss & & \\
\hline$<1000 \mathrm{ml}$ & 4 & 17.39 \\
\hline$>1000 \mathrm{ml}$ & 19 & 82.6 \\
\hline Blood transfusion & & \\
\hline Transfused & 7 & 30.4 \\
\hline Not transfused & 16 & 69.5 \\
\hline Complications & & \\
\hline Subtotal hysterectomy & 1 & 4.3 \\
\hline Re- laparotomy & 1 & 4.3 \\
\hline Puerperal pyrexia and sepsis & 2 & 8.6 \\
\hline Anaemia & 14 & 60.8 \\
\hline
\end{tabular}




\section{DISCUSSION}

Recently uterine leiomyomas are more encountered during pregnancy, because of delayed conception till late thirties. ${ }^{6}$ Caesarean myomectomy was practically absent from the obstetric literature until the last decade. ${ }^{4}$ The major problem associated with caesarean myomectomy is the risk of haemorrhage. Therefore the management of the fibroid encountered during caesarean section poses a therapeutic dilemma. Interval myomectomy is the usual practice. However several authors have published their result on caesarean myomectomy supporting it. In our study the mean age of patient was 31.2 years with highest no of patients are within 35 years $(73.9 \%)$. Majority of them were primigravida $(69.5 \%)$ and at term pregnancy $(78.2 \%)$. Though $82.6 \%$ patient had blood loss $>1000 \mathrm{ml}$, only 7 cases $(30.4 \%)$ had blood transfusion. Adesiyun et al reported only $9.1 \%$ of patients requiring blood transfusion in 22 cases of caesarean myomectomy. ${ }^{10}$ Kant Anita et al showed $50 \%$ requirement of blood transfusion in a series of nine cases. ${ }^{6}$ With regard to complication one case required hysterectomy due to torrential haemorrhage as it was located on the right cornu of the uterus. Hassan et al, in their series reported three hysterectomies out of ten patients those had undergone caesarean mymectomy. ${ }^{7}$ Another study by Exacoustos and Rosati showed nine similar cases of which three had severe haemorrhage followed by hysterectomy. ${ }^{8}$ Kwawukume reported uneventful caesarean myomectomy in 12 cases. ${ }^{4}$ In another case of our study relaparotomy was required due to post-operative intraperitoneal haemorrhage because of slippage of the ligature. The stump was religated and the uterus was preserved. Roman and Tabsh reported 111 cases of caesarean myomectomy without any complication. ${ }^{9}$ Post operative fever and sepsis was in $8.6 \%$ cases in present study. All these patients were in labour before operation, so elective caesarean section would have avoided this complication. Adesiyun et al had also reported $9.1 \%$ of puerperal pyrexia and sepsis in 23 similar cases. ${ }^{10}$ The hospital stay of all patients after the surgery was 8 days. Ehigiegba et al in a study advocated routine anterior wall caesarean myomectomy, most common morbidity being anaemia in $60 \%$ cases. ${ }^{11}$ Our study showed similarly $60.8 \%$ post operative anaemia. In contrast Adesiyun et all had reported anaemia only in $9.1 \%$ cases. ${ }^{10}$ In this study though intra operative haemorrhage of more than 1litre was in $82.6 \%$ cases, blood transfusion was given to only $30.4 \%$ of cases. This was to avoid unnecessary blood transfusion related complications. This might be the cause of high incidence of post-operative anaemia. Caesarean myomectomy is cost effective having other benefits like increased chance of vaginal birth after caesarean when removed from lower uterine segment along with decrease fibroid related complication in subsequent pregnancy. ${ }^{12,13}$ Moreover it avoids interval myomectomy, repeat surgery and anaesthesia exposure.

\section{CONCLUSION}

Myomectomy during caesarean section can be performed in selected cases with expert hand in well-equipped hospital having blood transfusion facility with minimal maternal morbidity.

Funding: No funding sources

Conflict of interest: None declared

Ethical approval: Not required

\section{REFERENCES}

1. Katz VL, Dotters DJ, Droegemeuller W. Complications of uterine leiomyomas in pregnancy. Obstet Gynecol 1989;73:593-6.

2. Depp R. Cesarean delivery. In: Obstetrics: normal and problem pregnancies 4th edition. Edited by: Gabbe SG, Niebyl JR, Simpson JL. New York: Churchill Livingstone; 2002:599.

3. Cunningham FG, Gant NF, Levenok KJ, Gilstrap LC, Hauth JC, Wenstrom KD, editors: Chapter 35: Abnormalities of the reproductive tract. In: Williams Obstetrics 21st edition. New York: McGraw Hill; 2001:930.

4. Kwawukume EY. Myomectomy during cesarean section. Int J Gynecol Obstet 2002;76:183-4.

5. Brown D, Fletcher H, Myrie M, Ried M. Caesarean myomectomy a safe procedure. A retrospective case controlled study. J Obstet Gynecol 1999; 19:139-141.

6. Kant A, Manuja S, Pandey R. Cesarean myomectomy. J Obstet Gynecol India 2007:57(2):128-130.

7. Hassan F, Arumugam K, Sivanesaratnam. Uterine leiomyomata in pregnancy. Int $\mathbf{J}$ Gyneacol Obstet 1991;34(1):45-8.

8. Exacoustos C, Rosati P. Ultrasound diagnosis of uterine myomas and complications in pregnancy. Obstet Gynecol 1993;82:97-101.

9. Roman AS, Tabsh KMA. Myomectomy at time of cesarean delivery; a retrospective cohort study. BMC Pregnancy and Child birth 2004;4:14-7.

10. Adesiyun AG, Ameh AC, Ojabo A. Myomectomy at Caesarean Section: descriptive study of clinical outcome in tropical setting. J Ayub Med Coll Abbottabad 2009;21(4):7-9.

11. Ehigiegba AE, Ande AB, Ojobo SI. Myomectomy during caesarean section. Int $\mathbf{J}$ Gynaecol Obstet 2001;75:21-5.

12. Omar SZ, Sivanesaratnam V, Damodaran P. Large lower segment myoma: Myomectomy at lower segment section - a report of two cases. Singapore Med J 1999;40:109-10.

13. Kwawukumeh EY. Caesarean myomectomy. Afr J Reprod Health 2002;6:38-43.

DOI: $10.5455 / 2320-1770 . i j r \operatorname{cog} 20140334$

Cite this article as: Pattanaik T, Pati BK, Samal S.

Caesarean myomectomy: a descriptive study of clinical outcome. Int J Reprod Contracept Obstet Gynecol 2014;3:172-4. 